\title{
Wide Range of Molecular Weight Distribution of Mitogenic Substance(s) in the Hot Water Extract of a Chinese Herbal Medicine, Bupleurum chinense
}

\author{
Shigeru Izumi, ${ }^{a}$ Naohito Ohno, ${ }^{a}$ Takuya Kawakita, ${ }^{b}$ Kikuo Nomoto, ${ }^{c}$ and \\ Toshiro YADOMAE*,a \\ Laboratory of Immunopharmacology of Microbial Products, School of Pharmacy, Tokyo University of Pharmacy and \\ Life Science, ${ }^{a}$ 1432-1 Horinouchi, Hachioji, Tokyo 192-03, Japan, Kampo Research Laboratories, Kanebo Co., Ltd., ${ }^{b}$ \\ Miyakojima-ku, Osaka 534, Japan and Department of Immunology, Medical Institute for Bioregulation, Kyushu \\ University, ${ }^{C}$ Higashi-ku, Fukuoka 812, Japan. Received November 18, 1996; accepted March 31, 1997
}

\begin{abstract}
In this study, we examined the contribution of lignin-like materials in lower molecular weight (MW) fractions from the hot water extract of Bupleuri Radix (Bupleurum chinense) (HWE-BR) for their immunopharmacological activities. Mitogenic activity was detected in all the fractions of MW ranges: lower than $1.0 \mathrm{kDa}, 1.0-3.5 \mathrm{kDa}$, 3.5-10 kDa, and $10-50 \mathrm{kDa}$. After $\mathrm{NaClO}_{2}$ treatment of these subfractions, UV spectra, ESR spectra, mitogenic activities on murine B-cells, and the activity of inducing nitric oxide in RAW 264.7 cells were significantly reduced, suggesting that lignin-like polyphenolic substance(s) of various MW might take part in these activities. The intensity of ESR spectra and mitogenic activities were stronger in higher MW subfractions, thus the content of stable radical species and/or the degrees of polymerization would be important for their immunopharmacological activities.
\end{abstract}

Key words lignin; polyphenol; B-cell mitogen; nitric oxide; Bupleurum chinense

Kampo medicines (KMs) have been applied to treat many kinds of acute and chronic disease. The efficacy of KMs have been accumulated from clinical experience spanning 2000 years in China. In recent years, many studies have been carried out to evaluate KMs pharmacological activities at the molecular level. The basic concept of the therapy using these medicines is to control the homeostasis of the whole body by the action of various components that normalize patients suffering from over-activated or depressed states. KMs have thus been considered as biological response modifiers (BRMs).

In Japan, more than $200 \mathrm{KMs}$ prescriptions have been used clinically. Bupleuri Radix (B. Radix) is a crude drug used in various prescriptions so-called Saikozai, which means prescriptions containing B. Radix (Saiko). One Saikozai prescription, Sho-saiko-to (SST) has been used very widely in the treatment of chronic diseases, e.g. hepatitis, asthma and nephrotic syndrome, and for the prevention of harmful after-effects of steroids and anticancer drugs. A recent study revealed that SST showed various immunomodulating activities and that each activity is mainly dependent on particular crude drugs: interferon-inducing activity by Glycyrrhizae Radix, interleukin (IL)-6 by Pinelliae Radix, and mitogenic activity by B. Radix. ${ }^{1)}$ This is similar to the observations that Yamashiki et al. reported, that Glycyrrhizae Radix and Scutellariae Radix are major components attributing to IL-1 $\beta$, tumor necrosis factor- $\alpha$, and granulocyte colony stimulating factor production from peripheral mononuclear cells. ${ }^{2)}$ These findings suggest that characteristic pharmacological activities are due at least in part to the immunopharmacological substances in crude drugs specific for each activity.

Previously, Oka et al. reported that the major mitogenic substances in the hot water extract of B. Radix (Bupleurum chinense) (HWE-BR) are from macromolecules (ca. 200 $\mathrm{kDa}$ ) defined as polyphenolic compounds and poly-

* To whom correspondence should be addressed. saccharides. ${ }^{3)}$ Immunopharmacologically active polyphenolic substances in Bupleurum chinense (B. chinense) are considered to have a lignin-like moiety based on the UV spectra and their susceptibility to $\mathrm{NaClO}_{2}$, a kind of polyphenol degrading reagent. Thus, lignin-like substances might play an important role in $B$. chinense, at least as a part of a mitogen.

Plant lignin, a major cell wall component, is thought to be generated through dehydrogenative polymerization from monolignols, such as $p$-coumaryl alcohol, coniferyl alcohol, and sinapyl alcohol, and catalyzed by peroxidase in the presence of $\mathrm{H}_{2} \mathrm{O}_{2}{ }^{4}$ ) Therefore, it is no wonder that lignin-like polyphenolic substances would show a wide range of molecular weight (MW) distribution. It should also be considered that the administration route of the crude drug is, in general, oral, and the physicochemical property of the substance, especially MW, is an important contributing factor for intestinal absorption. In this study, we performed further fractionation of HWE-BR and demonstrated that HWE-BR fractions with a MW of less than $50 \mathrm{kDa}$ also contain a lignin-like moiety and take part in the immunopharmacological activities of $B$. chinense.

\section{MATERIALS AND METHODS}

Mice Specific-pathogen-free male $\mathrm{C} 3 \mathrm{H} / \mathrm{HeJ}$ mice (6to 12-week-old) were obtained from Japan SLC Co. (Shizuoka, Japan).

Media RPMI 1640 medium (Nissui Seiyaku Co., Ltd., Tokyo, Japan) was supplemented with $5 \mathrm{~mm}$ HEPES (Sigma), $100 \mathrm{U} / \mathrm{ml}$ penicillin, and $100 \mu \mathrm{g} / \mathrm{ml}$ streptomycin (Meiji Seika Kaisha, Ltd., Tokyo, Japan).

Cells Macrophage-like cell line RAW 264.7 cells (RAW) (obtained from Riken Cell Bank, Tsukuba, Japan) were maintained in plastic culture flasks in RPMI 1640 medium supplemented with $10 \%$ heat-inactivated fetal 
bovine serum (FBS) (Moregate, Australia) (complete RPMI medium). For experiments, the cells were removed from the culture flask by wiping the bottom of the flask with a Cell Scraper ${ }^{\text {TM }}$ (Sumitomo Bakelite Co., Ltd., Tokyo, Japan), and were centrifuged (1200 rpm, $5 \mathrm{~min}$ ). Then, the cells were washed twice with RPMI medium and resuspended in complete RPMI medium to a concentration of $5 \times 10^{5}$ cells $/ \mathrm{ml}$.

Reagents B. Radix (Bupleurum chinense DC, Umbelliferae) was kindly provided from Kanebo Co., Ltd. (Osaka, Japan). Sephadex G-25 was purchased from Pharmacia LKB Biotechnology (Uppsala, Sweden). A BCA ${ }^{\mathrm{rM}}$ protein assay reagent was obtained from Pierce (Rockford, IL, U.S.A.). $p$-Nitrophenol (PNP), $p$-nitrophenylphosphate (P-NPP), and $2^{\prime}, 2^{\prime}$-iminodiethanol (diethanolamine) were purchased from Wako Pure Chemical Co., Ltd. (Osaka, Japan). Sulfanilamide, $N$-1-naphthylethylenediamine dihydrochloride, and $\mathrm{H}_{3} \mathrm{PO}_{4}$ used for Griess reagent were also obtained from Wako. Lipopolysaccharide (LPS) prepared from Escherichia coli 0111: B4, according to the method of Westphal, was purchased from Sigma.

Preparation and Fractionation of HWE-BR B. Radix $(200 \mathrm{~g})$ was boiled with 41 of de-ionized water (DIW) for $1 \mathrm{~h}$. After removing insoluble fragments with gauze mesh, the extract was concentrated to about $200 \mathrm{ml}$. This concentrated extract was precipitated with 41 of EtOH. After $1 \mathrm{~d}$, the resulting suspension was centrifuged $(3000 \mathrm{rpm}$, $5 \mathrm{~min}$ ) to give $\mathrm{EtOH}$ soluble and insoluble fractions. The EtOH insoluble fraction was dissolved in $200 \mathrm{ml}$ of DIW and centrifuged to collect the supernatant. The resulting supernatant was then dialyzed [molecular weight cut-off (MWCO): $1.0 \mathrm{kDa}]$ against DIW to give $\mathrm{MW}:<1.0 \mathrm{kDa}$ and $>1.0 \mathrm{kDa}$ fractions. The MW: $>1.0 \mathrm{kDa}$ fraction was dialyzed (MWCO: $3.5 \mathrm{kDa}$ ) against DIW to give MW: $1.0-3.5 \mathrm{kDa}$ and $>3.5 \mathrm{kDa}$ fractions. The $\mathrm{MW}:>3.5$ $\mathrm{kDa}$ fraction was dialyzed (MWCO: $10 \mathrm{kDa}$ ) against DIW to give MW: $3.5-10 \mathrm{kDa}$ and $>10 \mathrm{kDa}$ fractions. The MW: > $10 \mathrm{kDa}$ fraction was dialyzed (MWCO: $50 \mathrm{kDa}$ ) against DIW to give MW: $10-50 \mathrm{kDa}$ and $>50 \mathrm{kDa}$ fractions. These fractions were lyophilized.

Treatment with $\mathrm{NaClO}_{2}$ Fifty milligrams of each $\mathrm{MW}$ : $1.0-3.5 \mathrm{kDa}, 3.5-10 \mathrm{kDa}$, and $10-50 \mathrm{kDa}$ fraction was dissolved in DIW to a concentration of $1 \mathrm{mg} / \mathrm{ml}$ and then treated with $5 \mathrm{mg} / \mathrm{ml} \mathrm{NaClO}_{2}$ in $4 \% \mathrm{CH}_{3} \mathrm{COOH}$ for 40 $\min$ at $70^{\circ} \mathrm{C}$. After incubation, each reaction mixture was dialyzed (MWCO: $1.0 \mathrm{kDa}$ ) against DIW, and the nondialyzable fraction was lyophilized.

Spectral Measurements UV spectra were taken in an aqueous solution at room temperature with a Hitachi Model No. 557 spectrophotometer. ESR spectra were measured in solid state at room temperature with a JEOL JES-RE1X spectrometer.

Mitogen Assay Spleen cell suspensions from male $\mathrm{C} 3 \mathrm{H} / \mathrm{HeJ}$ mice were prepared by teasing spleens in cold RPMI 1640 medium. The cell suspensions were passed through a 200 gauge stainless steel sieve. The cell suspensions were centrifuged $(1200 \mathrm{rpm}, 5 \mathrm{~min})$, then washed twice with fresh medium. Serially diluted $50 \mu \mathrm{l}$ of sample solutions in RPMI medium and $200 \mu$ l of spleen cell suspensions $\left(2.5 \times 10^{6} \mathrm{cells} / \mathrm{ml}\right.$ in complete RPMI medium) were mixed and incubated in a flat-bottomed 96-well tissue culture plate for $72 \mathrm{~h}$ at $37^{\circ} \mathrm{C}$ under $5 \%$ $\mathrm{CO}_{2}$. The mitogenic activity of spleen cells was assessed by alkaline phosphatase activity especially expressed by B lymphocytes ${ }^{5-7)}$ as follows: $100 \mu 1$ of $0.1 \% p$-nitrophenylphosphate disodium salt (dissolved in $10 \%$ diethanolamine- $\mathrm{HCl}$ buffer, $\mathrm{pH}$ 9.5) was added to $50 \mu \mathrm{l}$ of cell suspension. Each mixture was incubated at $37^{\circ} \mathrm{C}$ for $30 \mathrm{~min}$. The absorption (Abs.) at $405 \mathrm{~nm}$ (reference: $630 \mathrm{~nm}$ ) was measured before and after incubation. $\Delta \mathrm{Abs}$. was used to subtract the light absorption originate from sample's color. $\triangle \mathrm{Abs}$. $=$ Abs. (after incubation) $-\mathrm{Abs}$. (before incubation). Released PNP content was quantified using PNP solution as a standard. The significance was evaluated by Student's $t$-test.

Cell Culture and Determination of Nitric Oxide (NO) as Nitrite Serially diluted $50 \mu$ l of sample solutions in RPMI medium and $200 \mu \mathrm{l}$ of RAW suspensions $\left(5 \times 10^{5}\right.$ cells $/ \mathrm{ml}$ in complete RPMI medium) were mixed and incubated in a flat-bottomed 96-well tissue culture plate for $24 \mathrm{~h}$ at $37^{\circ} \mathrm{C}$ under $5 \% \mathrm{CO}_{2}$. After incubation, culture fluids were assayed for nitrite contents by the Griess reaction as follows: $50 \mu \mathrm{l}$ of culture fluids were incubated with $50 \mu \mathrm{l}$ of Griess reagent composed of sulfanilamide $(1 \%), N-1$ naphthylethylenediamine dihydrochloride $(0.1 \%)$, and $\mathrm{H}_{3} \mathrm{PO}_{4}(2.5 \%)$ at room temperature for $10 \mathrm{~min}$. The absorbance at $550 \mathrm{~nm}$ was measured using the microplate reader MTP-32 (Corona Electric Co., Ltd., Tokyo). The nitrite level was quantitated using $\mathrm{NaNO}_{2}$ solution as a standard. The significance was evaluated by Student's $t$-test.

\section{RESULTS}

Physicochemical Properties of Fractionated HWEBR HWE-BR was prepared by hot water extraction followed by ethanol precipitation as described in Materials and Methods. HWE-BR was further fractionated by dialysis against de-ionized water to give subfractions having MW: $<1.0 \mathrm{kDa}, 1.0-3.5 \mathrm{kDa}, 3.5-10 \mathrm{kDa}, 10$ $50 \mathrm{kDa}$, and $>50 \mathrm{kDa}$. Table 1 shows the recovery of each fraction from $200 \mathrm{~g}$ of $B$. chinense. MW: $<1.0 \mathrm{kDa}$ fraction was the main fraction of HWE-BR.

A previous report suggested that the UV spectra of the polyphenolic substances in HWE-BR contributing to mitogenic activity resembled that of the commercially available polyphenol, lignin. ${ }^{3)}$ Thus, it was useful to examine the UV spectra of the fractions obtained in this experiment. As shown in Fig. 1, UV spectra of all fractions examined were similar to those of the commercially available lignin and the higher MW fraction of HWE-BR. In addition, these spectra were significantly reduced by $\mathrm{NaClO}_{2}$ treatment, a kind of polyphenol degrading reagent. These facts suggest that the lower MW fractions also contain significant amounts of polyphenolic substances, in addition to carbohydrates and proteins.

Sakagami et al. reported that either lignins isolated from lignified natural products or synthetic lignins prepared from phenylpropanoids through dehydrogenative polymerization gave an intense ESR signal at $g=2.003$ due to organic free radicals in the solid state. ${ }^{8,9)}$ Thus, measurement of ESR spectra was another useful method 
Table 1. Physicochemical Analysis of Fractionated HWE-BR ${ }^{a)}$

\begin{tabular}{|c|c|c|c|c|c|}
\hline Molecular weight (kDa) & $<1.0$ & $1.0-3.5$ & $3.5-10$ & $10-50$ & $>50$ \\
\hline $\begin{array}{l}\text { Yield (g) from Bupleuri Radix }(200 \mathrm{~g}) \\
\text { BCA }(\%)^{b)}\end{array}$ & $\begin{array}{l}7.04 \pm 0.98 \\
1.5\end{array}$ & $\begin{array}{l}0.28 \pm 0.11 \\
4.9\end{array}$ & $\begin{array}{l}0.55 \pm 0.26 \\
4.8\end{array}$ & $\begin{array}{c}0.59 \pm 0.11 \\
4.1\end{array}$ & $2.46 \pm 0.20$ \\
\hline Carbohydrates $(\%)^{b)}$ & 10.2 & 23.2 & 28.1 & 29.8 & N.D. ${ }^{c)}$ \\
\hline ESR-R.I. value & 0.1687 & 0.9890 & 1.0536 & 1.5017 & \\
\hline$g$ value & 2.0055 & 2.0053 & 2.0055 & 2.0054 & \\
\hline \multicolumn{6}{|l|}{ After $\mathrm{NaClO}_{2}$ treatment ${ }^{d)}$} \\
\hline Yield (mg) & & $10(20 \%)^{e)}$ & $10(20 \%)$ & $19(38 \%)$ & \\
\hline $\mathrm{BCA}(\%)$ & & 1.6 & 1.4 & 1.1 & \\
\hline Carbohydrates (\%) & & 18.3 & 16.7 & 34.9 & N.D. \\
\hline R.I. value & & 0.1613 & 0.2787 & 0.2592 & \\
\hline$g$ value & & 2.0055 & 2.0051 & 2.0053 & \\
\hline
\end{tabular}

a) HWE-BR was fractionated by dialysis as described in Materials and Methods. b) The content of BCA ${ }^{\mathrm{TM}}$ reaction positive substances was assessed as tannic acid. The content of carbohydrates was assessed as glucose. c) Not done. d) Each MW: $1.0-3.5 \mathrm{kDa}, 3.5-10 \mathrm{kDa}$, and $10-50 \mathrm{kDa}$ fraction was treated with $\mathrm{NaClO}_{2}$ as described in Materials and Methods. ESR spectrum of each resulting material was measured in solid state at room temperature with a JEOL JES-REIX spectrometer. e) \% recovery in parentheses.
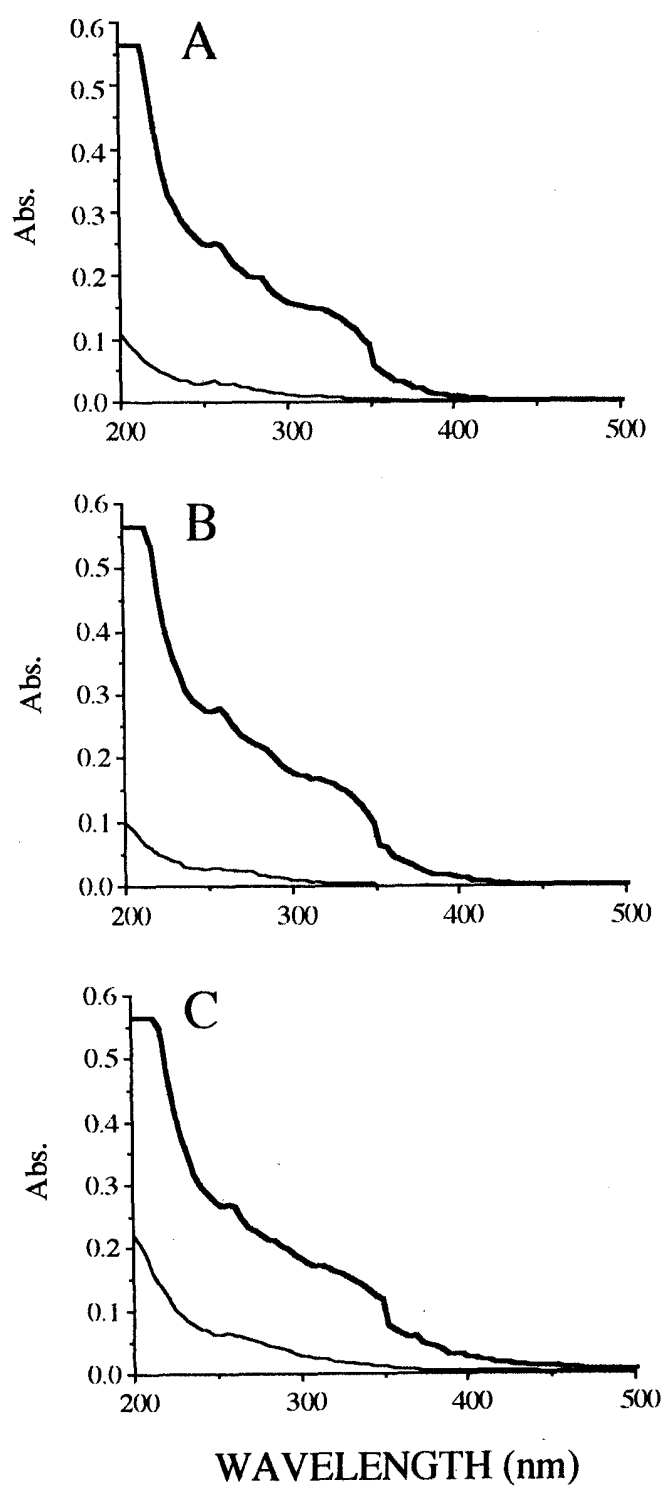

Fig. 1. UV Spectra of Fractionated HWE-BR

Each MW: $1.0-3.5 \mathrm{kDa}(\mathrm{A}), 3.5-10 \mathrm{kDa}(\mathrm{B})$, and $10-50 \mathrm{kDa}(\mathrm{C})$ fraction was treated with $\mathrm{NaClO}_{2}$, as described in Materials and Methods. Each resulting product was dissolved in DIW at a concentration of $50 \mu \mathrm{g} / \mathrm{ml}$, and each UV spectrum was measured at room temperature. Treated $(-)$ and parent samples $(-)$ to clarify the physicochemical properties of the mitogen in $B$. chinense as a lignin-like polyphenol. Thus, we next investigated whether the lower MW fractions of HWE-BR also gave an ESR signal at $g=2.003$. We obtained a value of relative intensity (R.I.) from ESR spectral measurement. R.I. values were obtained in comparison with the signal intensity of an external standard, $\mathrm{Mn}^{2+}$. As shown in Table 1, intense ESR signals were obtained from MW: $1.0-3.5 \mathrm{kDa}, 3.5-10 \mathrm{kDa}, 10-50 \mathrm{kDa}$ fractions. The R.I. value of MW: $<1.0 \mathrm{kDa}$ fraction was the weakest of all the fractions. These R.I. values show that the intensity of the ESR signals seems to be dependent on the amount of radical species in each fraction. $\mathrm{NaClO}_{2}$ treatment is a polyphenol degrading reaction. In this paper, we also examined the effect of $\mathrm{NaClO}_{2}$ on the physicochemical properties and immunopharmacological activities of these fractions. After $\mathrm{NaClO}_{2}$ treatment and dialysis, the recovery of each fraction was significantly reduced to about $20-40 \%$, and each R.I. value of the reteintates was significantly reduced, suggesting that these fractions contained significant amounts of polyphenolic substances and that their ESR signals might be dependent, at least in part, on substances having a lignin-like moiety. These observations were followed by the results that $\mathrm{NaClO}_{2}$ treatment more effectively reduced $\mathrm{BCA}^{\mathrm{TM}}$ reactive substances than carbohydrates (Table 1).

Immunopharmacological Activities of Fractionated HWE-BR The mitogenic activities of these fractions were compared, and it was found that the activity was stronger in higher MW fractions (Fig. 2). Figure 2 shows the mitogenic activity of $\mathrm{NaClO}_{2}$ treated fractions: $\mathrm{MW}$ : $1.0-3.5 \mathrm{kDa}$ (Fig. 2B), 3.5-10 kDa (Fig. 2C), and 10$50 \mathrm{kDa}$ fractions (Fig. 2D), and the activities of all these fractions were significantly reduced by this treatment.

Recently, we reported an in vitro study in which $\mathrm{KMs}$, including SST, showed NO-inducing activity on a macrophage cell line, RAW. ${ }^{10)}$ Dialysis of the water-soluble fraction of KMs made it clear that the macromolecular fraction of KMs contains specific substances to stimulate macrophage NO synthesis. In contrast, the corresponding low molecular weight fractions had no NO-inducing activity. This suggested that characteristic pharmacological activities would be due to the specific immunopharma- 

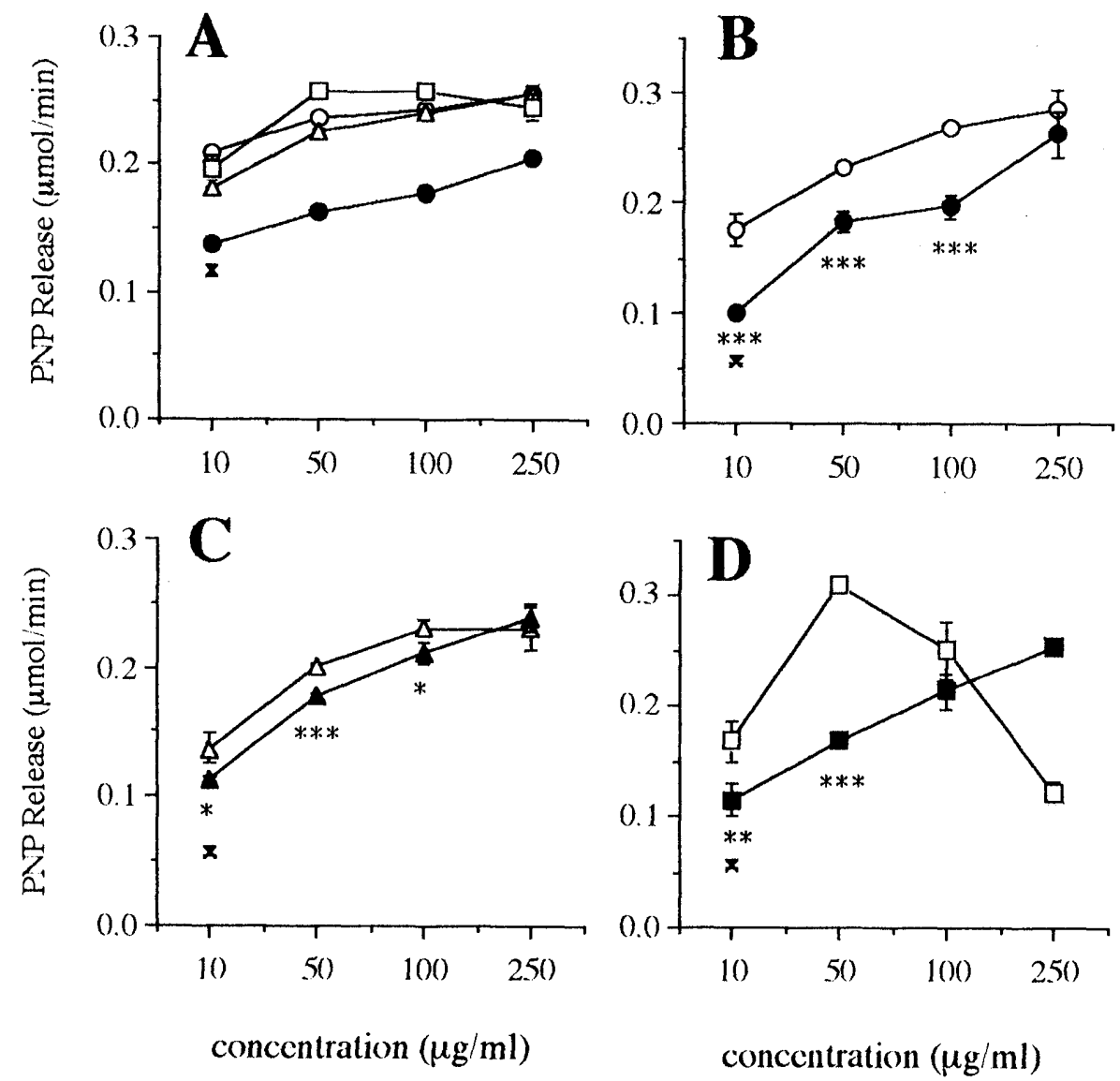

Fig. 2. Mitogenic Activity of Fractionated HWE-BR

Mitogenic activity of the samples including MW: $<1.0 \mathrm{kDa}$ fraction is shown in Fig. 2A; MW: $<10 \mathrm{kDa}()_{)}, \mathrm{MW} ;<1.0-3.5 \mathrm{kDa}(\mathrm{O}), \mathrm{MW}: 3.5-10 \mathrm{kDa}(\triangle)$, and MW: $10-50 \mathrm{kDa}(\square)$. Changes in mitogenic activity of each MW: $1.0-3.5 \mathrm{kDa}, 3.5-10 \mathrm{kDa}$, and $10-50 \mathrm{kDa}$ fraction after NaClO treatment is shown in Fig. $2 \mathrm{~B}(\mathbf{O})$, Fig. 2C $(\mathbf{A})$ and Fig. $2 \mathrm{D}(\boldsymbol{\square})$, respectively. The activity of the control group was shown as $x$. The data represents the mean $\pm S . D$. The significance was evaluated by Student's $t$-test against the corresponding parent sample. $* p<0.05 . * * p<0.01 . * * * p<0.001$.

cological substances included in KMs. As shown in Fig. $3 \mathrm{~A}$, all samples examined could induce NO from RAW. Similarity to the mitogenic activity, the NO-inducing activities of all these fractions were significantly reduced after $\mathrm{NaClO}_{2}$ treatment (Figs. 3B, C and D).

\section{DISCUSSION}

In this paper, we examined the contribution of lignin-like materials, having a MW of less than $50 \mathrm{kDa}$ fraction of HWE-BR, for their immunopharmacological activities. We prepared several subfractions by dialysis against water to obtain $\mathrm{MW}$ : $<1.0 \mathrm{kDa}, 1.0-3.5 \mathrm{kDa}, 3.5-10 \mathrm{kDa}$, $10-50 \mathrm{kDa}$, and $>50 \mathrm{kDa}$ fractions. The UV spectra, ESR signals, mitogenic activity and NO-inducing activity of all fractions were significantly reduced by $\mathrm{NaClO}_{2}$ treatment, suggesting the presence of a lignin-like moiety. Examination of the biological activities of the lignin-like substances from natural and synthetic sources showed various kinds of activities, suggesting that lignin-like substances are thus important as potential medicinal resources. ${ }^{1-13)}$ Meanwhile, mitogenic activity and NOinducing activity still remained positive even partially after $\mathrm{NaClO}_{2}$ treatment, suggesting that the lignin-like substances may contribute to these activities. Proteins were already reported to be considerable mitogenic substances. ${ }^{14)}$ However, in the case of the active part of the fraction of HWE-BR with a MW larger than $200 \mathrm{kDa}$, the intact protein part might not relate to the mitogenic activity, because pronase digestion did not abrogate the activity. ${ }^{3)}$

Preparation of KMs involves many kinds of interactions of constituents giving rise to various events, such as ion-pair formation, which generates water insoluble precipitates. ${ }^{15,16)}$ We previously reported that an amino acid, arginine, is one of the ingredients that appear to undergo some kind of modification during the preparation of KMs. ${ }^{17)}$ The decoction of crude drugs is associated with such a phenomena. Therefore, a certain part of the immunopharmacologically active substances in $\mathrm{KMs}$ might be end products from heat denaturation. Oka et al. recently reported that proteins in $B$. chinense might undergo heat denaturation during decoction. ${ }^{18)}$ Shinohara et al. reported that the mitogenic substance in Sclerotinia sclerotiorum IFO 9395 is a protein, named sclerogen, which is only active after heat denaturation. ${ }^{19,20)}$ Heat denatured substances such as polymerized proteins serve as active ingredients. Although, polyphenolic and heat denatured materials are included in most $\mathrm{KMs}$, it is important that not all of them show mitogenic activity and/or NOinducing activity. A certain specific functional group(s) might be required for these activities.

Our results suggest that the immunopharmacologically active substance in the lower MW fraction from HWE-BR 

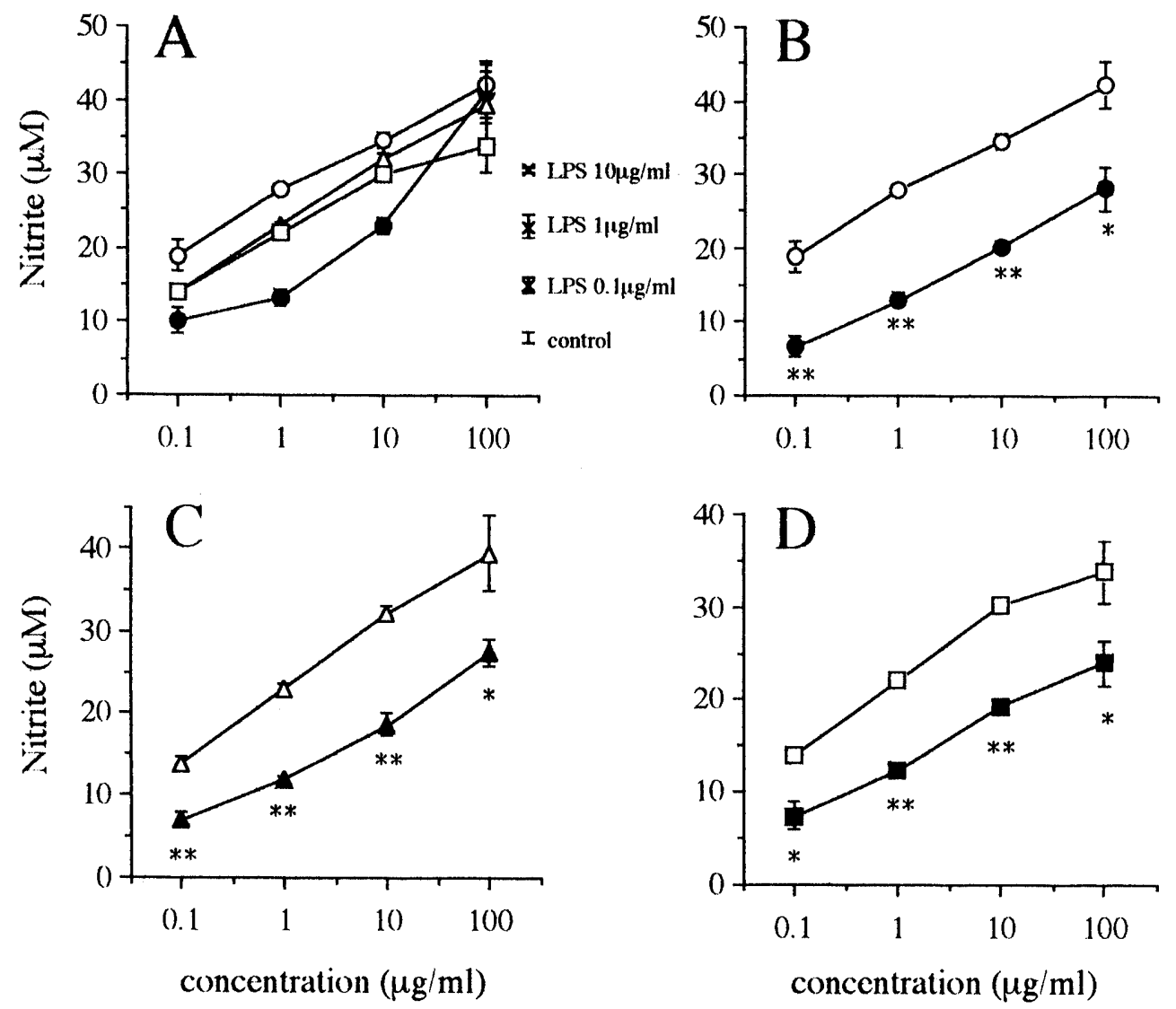

Fig. 3. NO Synthesis of RAW 264.7 cells by Fractionated HWE-BR

NO-inducing activity of the samples, including MW: $<10 \mathrm{kDa}$ fraction, is shown in Fig. 3A; MW: $<1.0 \mathrm{kDa}(\bullet), \mathrm{MW}:<1.0-3.5 \mathrm{kDa}(\mathrm{O})$, MW: $3.5-10 \mathrm{kDa}$ $(\triangle)$, and $\mathrm{MW}: 10-50 \mathrm{kDa}(\square)$. Changes in the NO-inducing activity of each $\mathrm{MW}: 1.0-3.5 \mathrm{kDa}, 3.5-10 \mathrm{kDa}$, and $10-50 \mathrm{kDa}$ fraction after $\mathrm{NaClO}_{2}$ treatment is shown in Fig. 3B $(\mathbf{-})$, Fig. 3C $(\mathbf{\Delta})$, and Fig. 3D $(\mathbf{\square})$, respectively. The data represents the mean \pm S.D. The significance was evaluated by Student's $t$-test against the corresponding parent sample. $* p<0.01, * * p<0.001$.

might be a polymer. Intense ESR signals were obtained at $g=2.005$, suggesting that stable organic free radicals, such as a phenoxy radical group, might contribute to the signals. The intensity of ESR signals and mitogenic activities seemed to be related to the MW ranges of substances. The intensity of ESR signals is thought to reflect at least the content of the radical species. Thus, mitogenic activity might be dependent on the frequency of charges. Another possibility is that the immunopharmacological activities of these materials might be dependent on degrees of polymerization.

Most KMs are used clinically via the oral route in Japan. Some of them have been considered immunomodulators. Clarification of the efficacy of the peroral administration of KMs on the immune system is thus needed. Recently, peroral administration of SST was reported to show several kinds of immunomodulation in mice: interferon induction, ${ }^{21)}$ immunoglobulin A production in Peyer's patch cells, ${ }^{22)}$ and activation of natural killer cells. ${ }^{23)}$ In the case of the macromolecular fraction of HWE-BR, augmentation of colony stimulating activity in serum was observed by peroral administration (manuscript in preparation). However, it is not yet generally accepted that macromolecules administered orally would be possible candidates for immunomodulation. HWE-BR examined in this study would contain lower MW lignin-like polyphenols as immunomodulators. Lower MW substances would be advantageous in terms of absorption from intestinal mucosa. From such a point of view, lower MW lignin-like mitogenic polyphenols are also important, even though they show less activity in vitro in comparison with macromolecules.

Acknowledgments We thank Mr. Y. Kobayashi and Miss Y. Mochizuki for their technical assistance.

\section{REFERENCES}

1) Matsuura K., Kawakita T., Nakai S., Saito Y., Suzuki A., Nomoto K., Int. J. Immunopharmacol., 15, 237-243 (1993).

2) Yamashiki M., Nishimura A., Hashimoto H., Kitagawa H., Yoshimasu H., Saito K., Koike M., Nakabayashi S., Sakaguchi M., Kosaka Y., Kampo Igaku, 20, 149-152 (1996).

3) Oka H., Ohno N., Iwanaga S., Izumi S., Kawakita T., Nomoto K., Yadomae T., Biol. Pharm. Bull., 18, 757-765 (1995).

4) Lewis N. G., Yamamoto E., Annu. Rev. Plant Physiol. Plant Mol. Biol., 41, 455-496 (1990).

5) Burg D. L., Feldbush T. L., J. Immunol., 142, 381-387 (1989).

6) Marquez C., Toribio M. L., Marcos M. A. R., De la Hela A., Barcena A., Pezzi L., Martinez-A. C., J. Immunol., 142, 3187-3192 (1989).

7) Souvannavong V., Adam A., Immunol. Lett., 29, 247-252 (1990).

8) Sakagami H., Oh-hara T., Kaiya T., Kawazoe Y., Nonoyama M., Konno K., Anticancer Res., 9, 1593-1598 (1989).

9) Sakagami H., Oh-hara T., Kohda K., Kawazoe Y., Chem. Pharm. Bull., 39, 950-955 (1991).

10) Izumi S., Ohno N., Miura N. N., Takada K., Yadomae T., Drug Dev. Res., 36, 112-118 (1995).

11) Sakagami H., Kawazoe Y., Komatsu N., Simpson A., Nonoyama 
M., Konno K., Yoshida T., Kuroiwa Y., Tanuma S., Anticancer Res., 11, 881-888 (1991).

12) Nakashima H., Murakami T., Yamamoto N., Naoe T., Kawazoe Y., Konno K., Sakagami H., Chem. Pharm. Bull., 40, 2102-2105 (1992).

13) Shimizu N., Naoe T., Kawazoe Y., Sakagami H., Nakashima H., Murakami T., Yamamoto N., Biol. Pharm. Bull., 16, 434 436 (1993).

14) Tachibana Y., Kawanishi K., Planta Med., 58, 250-254 (1992).

15) Noguchi M., Hashimoto Y., Shoyakugaku Zasshi, 37, 56-61 (1983).

16) Kano Y., Konoshima M., Shoyakugaku Zasshi, 32, 53-58 (1978).

17) Izumi S., Ohno N., Kawakita T., Nomoto K., Yadomae T., Pharm. Pharmacol. Lett., 6, 37-41 (1996).
18) Oka H., Ohno N., Izumi S., Kawakita T., Miura O., Nomoto K., Yadomae T., Pharm. Pharmacol. Lett., 3, 88-91 (1993).

19) Shinohara H., Ohno N., Yadomae T., Chem. Pharm. Bull., 38, 2219-2223 (1990).

20) Shinohara H., Ohno N., Yadomae T., Chem. Pharm. Bull., 40, 2562-2564 (1992).

21) Kawakita T., Nakai S., Kumazawa Y., Miura O., Yumioka E., Nomoto K., Int. J. Immunopharmacol., 12, 515-521 (1990).

22) Tauchi Y., Yamada A., Kawakita T., Saito Y., Suzuki A., Yosikai Y., Nomoto K., Immunopharmacol. Immunotoxicol., 15, 251-272 (1993).

23) Kaneko M., Kawakita T., Tauchi Y., Saito Y., Suzuki A., Nomoto K., Immunopharmacol. Immunotoxicol., 16, 41-53 (1994). 